\title{
Acute appendicitis: Analysis of 518 histopathologically diagnosed cases at the Kathmandu University Hospital, Nepal
}

\author{
Makaju $\mathbf{R}^{1}$, Mohammad $\mathbf{A}^{2}$, Shakya $\mathbf{A}^{3}$
}

${ }^{1}$ Assistant Professor, ${ }^{2}$ Professor \& Head, ${ }^{3}$ Pathologist, Department of Pathology, Kathmandu University Medical School (KUMS), Dhulikhel, Nepal.

\begin{abstract}
Background: Appendicitis is important as it is a common surgical emergency. There is no medical treatment for it, timely surgery is mandatory to prevent morbidity and mortality.

Objectives: The objective of this study was to analyse the pathologic findings, the demographics, and, look for the existence of the so called aetiopathogenetic factors in the context of current prevailing beliefs regarding acute appendicitis, the most common current reason for emergency abdominal surgery.

Materials and methods: This was a retrospective study. It was carried out at the Kathmandu University Hospital, Dhulikhel, Kavre, Nepal. All histopathologically diagnosed cases of acute appendicitis during the period January 1, 2004 to April 30, 2010 were included. Their macrospcopic and light microscopic examination findings were analyzed.

Results: A total of 518 histopathologically diagnosed cases of acute appendicitis were found. Age distribution of these cases was between 6 to 84 years. Mean age was 30. 94_ 15.75 years. Sex distribution consisted of $313(60.42 \%)$ cases in males and $205(39.58 \%)$ cases in females. Fecalith in the appendiceal lumen was seen only in $8(1.54 \%)$ of cases. Granuloma and carcinoid was seen in $3(0.58 \%)$ and $1(0.19 \%)$ cases respectively. Perforation was seen in $11(2.12 \%)$ cases. Foreign bodies, gallstones, strictures, helminthic infection, carcinoma or any other obvious/apparent aetiologic/ pathogenetic lesions/findings were not seen in any of the cases. Histopathologically staged distribution revealed that $180(34.75 \%)$ cases were of early acute appendicitis, $250(48.26 \%)$ cases were of acute suppurative appendicitis, and 88 $(16.99 \%)$ cases were of acute gangrenous appendicitis.

Conclusion: This study did not confirm the existing popular notion that luminal obstruction is the pathogenetic hallmark for acute appendicitis. Therefore, further research on this common surgical emergency is surely warranted.
\end{abstract}

Key words: Acute appendicitis, fecalith, gangrenous

\begin{abstract}
$\mathrm{A}$ ppendicitis is now not generally thought to be an interesting subject for research, but it remains an important disease. It is important because it is a common surgical emergency, there is no medical treatment for it, timely surgery is mandatory to prevent morbidity and mortality, which is about $2 \%$ associated with perforation. Furthermore, there is only speculation as to its aetiology and pathogenesis; but, no definite scientific proof of it, despite the phenomenal medical advancements and development of all the diagnostic and investigative tools. Therefore, it is thought that further collection of data on acute appendicitis is important. We did this study to see how our cases fit or do not fit into this mould of current concepts and beliefs.
\end{abstract}

\section{Materials and methods}

This retrospective study was carried out at the Kathmandu University Hospital, Dhulikhel, Kavre, Nepal. All histopathologically diagnosed cases of acute appendicitis from January 1, 2004 to April 30,
2010 were included. All cases were grouped into three histopathologic categories according to the stages of progression of disease by gross and light microscopic examination as follows:

Appendices with dull serosal surface on gross examination with scant transmural and perivascular neutrophilic infiltrates on microscopic examination were categorized as early appendicitis. Appendices with fibrinopurulent exudates on serosal surface upon gross examination and with dense transmural neutrophilic infiltrates with focal abscess formation, ulceration and necrosis of mucosa microscopically were categorised as

\footnotetext{
Correspondence

Dr. Ramesh Kumar Makaju

Assistant Professor

Department of Pathology

Kathmandu University Medical School (KUMS)

Kathmandu University Hospital Dhulikhel, Nepal

E-mail:makajuram@yahoo.com
} 
suppurative appendicitis. Grossly, green-black necrotic appendices, with areas of hemorrhagic ulceration of the mucosa, and necrosis through the wall extending to the serosa microscopically were categorised as acute gangrenous appendicitis.

Specifically, presence or absence of any cause of luminal obstructions was noted. Data were analyzed by using Microsoft Excel 2003.

Result

A total of 518 histopathologically confirmed cases of acute appendicitis were seen from January 1, 2004 to

Table 1: Age distribution of acute appendicitis

\begin{tabular}{|c|c|c|}
\hline Age groups & Number of cases & Percent \\
\hline $0-10$ & 77 & 5.21 \\
\hline $11-20$ & 116 & 22.39 \\
\hline $21-30$ & 154 & 21.81 \\
\hline $31-40$ & 113 & 8.88 \\
\hline $41-50$ & 46 & 5.79 \\
\hline $51-60$ & 30 & 4.05 \\
\hline $61-70$ & 21 & 1.74 \\
\hline $71-80$ & 9 & 0.39 \\
\hline $81-90$ & 2 & $\mathbf{1 0 0}$ \\
\hline Total & $\mathbf{5 1 8}$ & \\
\hline
\end{tabular}

Table 2: Histopathologic distribution of acute appendicitis

\begin{tabular}{|l|c|c|}
\hline Histopathologic type & Number of cases & Percent \\
\hline Early acute appendicitis & 180 & 34.75 \\
\hline Acute suppurative appendicitis & 250 & 48.26 \\
\hline Acute gangrenous appendicitis & 88 & 16.99 \\
\hline Total & $\mathbf{5 1 8}$ & $\mathbf{1 0 0}$ \\
\hline
\end{tabular}

Table3: Presence of other pertinent findings

\begin{tabular}{|l|c|c|}
\hline Other pertinent findings & Number of cases & Percent \\
\hline Fecalith & 8 & 1.54 \\
\hline Perforation & 11 & 2.12 \\
\hline $\begin{array}{l}\text { Granuloma consistent with } \\
\text { tuberculosis }\end{array}$ & 3 & 0.58 \\
\hline Carcinoid & 1 & 0.19 \\
\hline
\end{tabular}

\section{Discussion}

The worm-like structure, the vermiform appendix, is an appendage to the caecum with no obvious function in the Homo sapiens. Amyan, a surgeon of the English army, performed an appendicectomy in 1735 to remove a perforated appendix. However, until 1886 , inflammation in the right lower quadrant of the abdomen was considered a non-surgical disease of the caecum (typhilitis or perityphilitis). Reginald $\mathrm{H}$.
April 30, 2010. Age distribution of these cases was as shown in table 1. The age range was between 6 to 84 years. Mean age was $30.94 \pm 15.75$ years. Sex distribution consisted of $313(60.42 \%)$ cases in males and $205(39.58 \%)$ cases in females. Histopathologic distribution was as shown in table 2. Presence of other pertinent findings, including fecolith, perforation, granuloma consistent with tuberculosis, and carcinoid was as shown in table 3 . 
which became the basis of diagnosis and treatment of acute appendicitis. Since then, efforts of medical science towards learning and understanding about the appendicitis has brought us to the current concepts and believes that the most important factor in the pathogenesis of acute appendicitis is the obstruction of the lumen of the appendix as the pathogenetic hallmark, most commonly by faecolith formed by accumulation and inspissation of faecal matter around vegetable fibres, which are found in at least three-fourths of acutely inflamed appendices and in virtually all that are gangrenous ${ }^{2,3,4}$. The other causes of obstruction found are inspissated barium, vegetable, fruit seeds and other foreign bodies, stricture, intestinal worms (ascarids), ball of worms (Oxyuriasis vermicularis), gallstone and tumours, including carcinoid, the frequency of which is $l o w^{5,6}$.

However, in our series, faecolith was found to be present only in $8(1.54 \%)$ cases. Amongst other various believed causes of obstruction, in our series only 3 cases $(0.58 \%)$ of granuloma were found. One case $(0.19 \%)$ of carcinoid was found, comparable to the occurrence of carcinoid tumour up to $0.5 \%$ of appendicectomy specimens $^{7,8}$.

Also the current concept and belief is that acute appendicitis is rare in Asia and Africa ${ }^{9}$. But it is relatively more common in U.S.A. and Europe ${ }^{2}$. This difference has been explained on the basis of a dietary variance, the highest risk occurring with high-protein, low-fibre $\operatorname{diet}^{10}$. In our series in a hospital in Nepal, a country in Asia, out of a total of 6,945 surgical pathology cases seen, $518(7.46 \%)$ consisted of histopathologically confirmed cases of acute appendicitis. This number, by extrapolation to the total representative population is in concurrence with the above popular prevailing belief.

The age predominance is reported to be in the 10-30 years age group 9 . In our series it was in the 11 to 40 years age group. The sex predominance is reported to be slightly in males ${ }^{11}$. Our present study also showed male predominance, however, with higher male to female ratio consisting of 1.53:1.

Histopathologic distribution of acute appendicitis in one series consisted of early appendicitis $35.33 \%$, suppurative appendicitis $51.20 \%$ and gangrenous appendicitis $13.47 \% \%^{12}$. This is similar to the findings of our present study.

Granulomatous inflammation of appendix due to tuberculosis occurs only in $0.1 \%$ to $3 \%$ cases of all appendectomies ${ }^{13}$. Comparably in our study, granulomatous inflammation consistent with tuberculosis was seen in three cases $(0.58 \%)$.

\section{Conclusion}

This study did not substantiate the prevailing popular belief that the main pathogenetic hallmark of acute appendicitis is luminal obstruction. Furthermore, this study did indeed indicate that despite the phenomenal advances in medical science and all the diagnostic and investigative tools at our disposal today and our more than 100 years of experience with acute appendicitis, we do not yet know the definite aetiopathogenesis of this condition most commonly requiring emergency abdominal surgery.

Therefore, we conclude that further research is surely warranted on this subject with the hope that a better understanding of aetiopathogenesis would help in better management with reduction in the morbidity and mortality and possibly even in prevention of acute appendicitis.

\section{References}

1. Williams GR. Presidential address: a history of appendicitis. Ann Surg. 1983;197(5):495-506.

2. Liu C, Crawford JM. The Gastrointestinal Tract. In: Kumar V, Abbas AK, Fausto N, (editors). Robins and Cotran Pathologic Basis of Disease. 7th ed. Philadelphia: Saunders; 2004. p.797875.

3. Hasler WL. Owyang C. Disorders of alimentary tract. In: Fauci AS, Braunwald E, Kasper DL, Hausen SL, Longo DL, Jameson JL, Loscalzo, (editors). Harrison's Principles of internal medicine, volume II. 17th ed. New York: McGraw Hill; 2008.p. 1831-917.

4. Fine G, MA CK. Alimentary tract. In: Kissane JM, (editor). Anderson's Pathology. 9th ed. St. Louis: CV Mosby Co; 1990. p. 1153-98.

5. Gupta SC, Gupta AK, Keswani NK, Singh PAI, Tripathi AK, Krishna V. Pathology of tropical appendicitis. J Clin Pathol. 1989;42:1169-72.

6. Lampertico P. Clinicopathologic considerations on 9952 appendices removed at the Busto Arsizio Hospital from1966 to 1989. Pathologica. 1990;82:719-32.

7. Marshall JB, Bodnarchuk G. Carcinoid tumors of the gut. Our experience over three decades and review of the literature. J Clin Gastroenterol. 1993;16:123-9.

8. Jetmore AB, Ray JE, Gathright JB Jr, McMullen KM, Hicks TC, Timrncke AE. Rectal carcinoids: the most frequent carcinoid tumor. Dis Colon Rectum. 1992;35:717-25.

9. Fenton, AH. Appendicitis, acute. Amer J of Surg1990;160:291-93. 
10. Rosai, J. Gatrointestinal tract. In: Rosai, J (editor). Ackerman's Surgical Pathology Volume.1. 9th ed. St. Louis: CV Mosby Co.p.615-871.

11. Foster H. McA, Webb SJ. Appendicitis and appendicectomy in a Melanesian population. Br. J. Surg. 1989;76:368-9.
12. Nabipour F, Mohammad BD. Histopathological features of acute appendicitis in Kerman-Iran from 1997 to 2003. American J. Environmental Sci. 2005;1(2):130-32.

13. Gupta S, Kaushik R, Kaur A, Attri AK. Tubercular appendicitis-a case report. World J Emerg Surg. 2006;1:22. 